\title{
PERÍOdOS DE INTERFERÊNCIA DE Brachiaria plantaginea NA Cultura do Milho Na Região Sul do Rio Grande do Sul ${ }^{1}$
}

\author{
Interference Periods of Brachiaria plantaginea in Corn Crops in Southern Rio Grande do Sul
}

\author{
GALON, L. ${ }^{2}$, PINTO, J.J.O. ${ }^{3}$, ROCHA, A.A. ${ }^{4}$, CONCENÇO, G. ${ }^{2}$, SILVA, A.F..$^{2}$, ASPIAZÚ, I. ${ }^{2}$, \\ FERREIRA, E.A. ${ }^{2}$, FRANÇA, A.C. ${ }^{2}$; FERREIRA, F.A. ${ }^{5}$, AGOSTINETTO, D. ${ }^{3}$ e PINHO, C.F. ${ }^{6}$
}

\begin{abstract}
RESUMO - Os períodos de convivência das espécies daninhas têm grande influência no crescimento das plantas e na produtividade das culturas. Desse modo, objetivou-se com este trabalho determinar os períodos de competição, anterior à interferência (PAI), o crítico de prevenção à interferência (PCPI) e o período total de prevenção da interferência (PTPI) de $B$. plantaginea sobre a cultura do milho na Região Sul do Rio Grande do Sul. Adotou-se o delineamento experimental de blocos casualizados, no sistema de cultivo convencional com quatro repetições. Os tratamentos consistiram em manter a cultura do milho na presença e ausência de $B$. plantaginea por $0,7,14,21,28,35$ e 42 dias após a emergência (DAE) da cultura. B. plantaginea originou-se do banco de sementes do solo, com população média de 312 plantas $\mathrm{m}^{-2}$. Foram amostradas e analisadas 10 plantas de milho em cada unidade experimental, com vistas à avaliação da altura de plantas e da inserção da espiga $(\mathrm{cm})$, do comprimento de espigas $(\mathrm{cm})$, do número de fileiras por espiga, número de grãos por fileira e número de grãos por espiga, além da produtividade de grãos, que foi determinada pela colheita de três linhas centrais da área útil em cada unidade experimental. Considerando $5 \%$ de tolerância na redução da produção, conclui-se que o período total de prevenção à interferência (PTPI) foi de $27 \mathrm{DAE}$; o período que antecede a interferência (PAI), de $11 \mathrm{DAE}$; e o período crítico de prevenção à interferência (PCPI), de 11 a $27 \mathrm{DAE}$.
\end{abstract}

Palavras-chave: competição, componentes do rendimento, Zea mays.

\begin{abstract}
Weed control period have great influence on plant growth and crop productivity. The objective of this work was to determine the competition periods, both previous to interference and critical interference prevention of B. plantaginea on corn crop in Southern Rio Grande do Sul. The trial was conducted in a completely randomized block design, under conventional tillage system, with four replications. The treatments consisted of maintaining the culture of corn in the presence and absence of B. plantaginea for $0,7,14,21,28,35$ and 42 days after crop emergence (DAE). B. plantaginea emerged from the soil seed bank, with an average population of 312 plants $\mathrm{m}^{-2}$. Ten corn plants were sampled and analyzed in each experimental assay to obtain the following variables: plant and ear insertion height (cm), ear length (cm), number of rows per ear, number of grains per row, number of grains per ear. Grain productivity was determined by collecting three central lines of the useful area in each experimental unit. Considering a 5\% tolerance in production reduction, it was concluded that the total period of interference prevention was $27 \mathrm{DAE}$, the period preceding interference was $11 \mathrm{DAE}$ and the critical period of interference prevention was 11 and 27 DAE.
\end{abstract}

Keywords: competition, yield components, Zea mays.

1 Recebido para publicação em 13.2.2008 e na forma revisada em 20.5.2008.

2 Doutorando do Programa de Pós-Graduação em Fitotecnia da Universidade Federal de Viçosa - DFT/UFV, Bolsista do CNPq, Viçosa-MG, 36570-000; <galonleandro@ig.com.br> (autor para correspondência); ${ }^{3}$ Professor do Dep. de Fitossanidade da Faculdade de Agronomia Eliseu Maciel da Universidade Federal de Pelotas (DFs/FAEM/UFPel), Caixa postal 354, 96010-900, Capão do Leão-RS; ${ }^{4}$ Aluno do Programa de Pós-Graduação em Zootecnia - DZO/UFV; ${ }^{5}$ Professor do DFT/UFV, Bolsista em Produtividade de Pesquisa do CNPq; ${ }^{6}$ Aluna de graduação de Agronomia da FAEM/UFPel.

Planta Daninha, Viçosa-MG, v. 26, n. 4, p. 779-788, 2008 


\section{INTRODUÇÃO}

A cultura do milho é uma das mais importantes e tradicionais do Brasil, com aproximadamente 13 milhões de hectares e produtividade média de $3,2 \mathrm{t} \mathrm{ha}^{-1}$ (CONAB, 2007), sendo componente essencial na alimentação animal e humana. Essa produtividade está aquém daquelas obtidas em lavouras que utilizam tecnologias modernas. Entre os muitos fatores responsáveis pela baixa produtividade da cultura do milho, destacam-se a interferência das plantas daninhas e o manejo ineficiente destas.

Estima-se que as perdas na cultura do milho em função da competição com as plantas daninhas sejam da ordem de 13\% (Carvalho et al., 2007); em muitas situações onde nenhuma medida de controle é adotada, essa redução pode chegar a 85\% (Carvalho et al., 2007) ou mais de 90\% (Merotto Jr. et al., 1997).

Isso ocorre em função da comunidade infestante da área (composição específica, população, distribuição e época de emergência), da própria cultura (híbrido, espaçamento entre linhas, densidade de semeadura e adubação), das condições edafoclimáticas reinantes no período, além do estádio fenológico da cultura.

A época de início do controle de plantas daninhas apresenta grande influência no crescimento das plantas e na produtividade de grãos do milho (Rizzardi et al., 2004). Quando a cultura emite a quinta folha, as plantas infestantes podem causar redução dos componentes do rendimento de grãos, da altura da inserção das espigas, do comprimento médio destas, da altura das plantas e do número médio de grãos por fileira (Fancelli \& Dourado Neto, 2000). A população e o número de espigas por planta diminuem com o atraso na época de controle (Zagonel et al., 2000). Mesmo que a cultura seja considerada competitiva, pode ser severamente afetada pela interferência de plantas daninhas, reduzindo o crescimento e a produtividade de grãos (Constantin et al., 2007).

Em relação à época e duração da convivência da cultura com as plantas daninhas, Pitelli \& Durigan (1984) referem-se ao periodo anterior à interferência (PAI) como o período, a partir da semeadura, durante o qual a cultura pode conviver com as plantas daninhas sem que ocorra redução na produtividade. Os autores denominaram período total de prevenção à interferência (PTPI) o período, a partir da semeadura ou emergência da cultura, durante o qual as plantas daninhas devem ser controladas para que a cultura possa manifestar plenamente seu potencial produtivo. Quando o PTPI é mais longo que o PAI, define-se um intervalo delimitado por ambos e denominado período crítico de prevenção da interferência (PCPI), que representa o período em que efetivamente a cultura deve estar livre da interferência das plantas daninhas. Esse tipo de comportamento viabiliza o uso de práticas instantâneas de controle das plantas daninhas.

Na cultura do milho, vários autores estudaram os períodos de interferência das plantas daninhas, encontrando, para o PAI, valores variáveis de 15 até 45 dias após a emergência (Pitelli \& Durigan, 1984; Pitelli, 1985; Sales, 1991). Já para o período crítico, os valores encontrados foram de 28 dias (Hall et al., 1992), ou 34 a 40 (Singh et al., 1996) ou ainda 56 dias após a emergência (DAE) da cultura (Haan et al., 1994). Essa variação pode ser atribuída às diferentes condições de fertilidade e umidade do solo, época de cultivo, espécies de plantas daninhas presentes na lavoura, cultivar, arranjo e população de plantas (Severino et al., 2005; Constantin et al., 2007; Duarte et al., 2007). Esses trabalhos forneceram informações com base em um período de tempo definido, ou seja, dias após a emergência em que a variação é função de características edafoclimáticas, da cultura e da espécie daninha avaliada, e também de acordo com o nivel tecnológico adotado pelo agricultor.

No entanto, para a Região Sul do Rio Grande do Sul não há pesquisas visando o estudo da competição de B. plantaginea, espécie infestante considerada companheira da cultura do milho, de alto potencial competitivo e que explora eficientemente os recursos disponiveis no ambiente, reduzindo a disponibilidade para a cultura. Essa espécie causa prejuízos consideráveis à produtividade e à qualidade de grãos, sendo uma das espécies daninhas de maior ocorrência na região Sul do Brasil (Fleck, 1996; Kissmann \& Groth, 1997), que pode ocasionar a redução de até $90 \%$ na 
produtividade de grãos de milho caso nenhum controle seja realizado (Merotto Jr. et al., 1997). Além disso, sua importância como planta daninha é dependente do sistema de cultivo adotado. Silva et al. (2008) constataram que no sistema convencional de cultivo $80 \%$ da massa seca das plantas daninhas foi atribuída a $B$. plantaginea, afetando diretamente o rendimento das culturas.

O número e o tamanho de espigas de milho normalmente são os parâmetros mais afetados pela interferência das plantas daninhas (Mundstock \& Silva, 1989; Balbinot Jr. \& Fleck, 2005). Com isso, a competição das plantas daninhas reduz a produtividade de grãos do milho (Merotto Jr. et al., 1997; Vidal et al., 2004). Nesse sentido, tornam-se necessárias pesquisas para atender às necessidades de diferentes regiões do País e conhecer a sensibilidade da cultura do milho à competição com $B$. plantaginea, com o intuito de fornecer subsídios para o planejamento de programas de manejo integrado desta espécie daninha e os períodos de interferência ocorrentes na cultura.

Objetivou-se com este trabalho determinar os períodos denominados de anterior à interferência (PAI), período crítico de prevenção da interferência (PCPI) e período total de prevenção da interferência (PTPI) de $B$. plantaginea sobre a cultura do milho na região sul do Rio Grande do Sul.

\section{MATERIAL E MÉTODOS}

O experimento foi conduzido em campo no Centro Agropecuário da Palma (CAP), pertencente à Universidade Federal de Pelotas (UFPel), município do Capão do Leão-RS, em sistema convencional de semeadura, com aração seguida de gradagem. O solo da área experimental foi classificado como Argissolo Vermelho-Amarelo, pertencente à Unidade de Mapeamento Pelotas (Embrapa, 1999), com as seguintes características: $\mathrm{pH}$ (água) $=5,8$; matéria orgânica $=1,94 \%$; argila $=16 \% ; \mathrm{P}=$ $5,1 \mathrm{mg} \mathrm{dm}^{-3} ; \mathrm{K}=35 \mathrm{mg} \mathrm{dm}{ }^{-3} ; \mathrm{Ca}^{+2}=$ $2,6 \mathrm{cmol}_{\mathrm{c}} \mathrm{dm}^{-3} ; \mathrm{Mg}^{+2}=1 \mathrm{cmol}_{\mathrm{c}} \mathrm{dm}^{-3} ; \mathrm{Al}^{+3}=$ $0,2 \mathrm{cmol}_{\mathrm{c}} \mathrm{dm}^{-3} ; \mathrm{H}+\mathrm{Al}=2,5 \mathrm{cmol}_{\mathrm{c}} \mathrm{dm}^{-3} ; \mathrm{e}$ $\mathrm{CTC}_{\text {efetiva }}=3,9 \mathrm{cmol}_{\mathrm{c}} \mathrm{dm}^{-3}$.
O delineamento experimental adotado foi de blocos casualizados, com quatro repetições. As unidades experimentais mediam $20 \mathrm{~m}^{2}$ (4 x $5 \mathrm{~m})$, com área útil de $10 \mathrm{~m}^{2}(2,5 \times 4 \mathrm{~m})$. Utilizou-se o híbrido triplo de milho Pioneer3063, de ciclo precoce, semeado em espaçamento entre linhas de $0,80 \mathrm{~m}$, com densidade média de 4,5 plantas por metro, obtendo-se população aproximada de 55.000 plantas ha ${ }^{-1}$. A correção da fertilidade do solo foi realizada de acordo com as recomendações técnicas, com a aplicação de $200 \mathrm{~kg} \mathrm{ha}^{-1}$ de adubo da fórmula 5-20-20 (N, $\mathrm{P}_{2} \mathrm{O}_{5}$ e $\left.\mathrm{K}_{2} \mathrm{O}\right)$. Quando as plantas de milho atingiram o estádio de seis a oito folhas, realizou-se a adubação nitrogenada, em cobertura, aplicando $115 \mathrm{~kg} \mathrm{ha}^{-1}$ de N na forma de uréia (Indicações..., 2006).

Realizou-se o levantamento populacional da área experimental, o qual apresentou população média de 312 plantas $\mathrm{m}^{-2}$ de $B$. plantaginea, sendo estas plantas provenientes do banco de sementes do solo. As demais plantas daninhas existentes na área experimental foram eliminadas manualmente.

Os tratamentos foram separados em dois modelos de interferência: no primeiro, a cultura do milho conviveu com $B$. plantaginea por períodos crescentes de $0,7,14,21,28,35$ e 42 dias após a emergência; e, no segundo, a cultura foi mantida livre da infestação pelos mesmos períodos descritos anteriormente.

Aos 120 dias após a emergência (DAE), foram amostradas e analisadas 10 plantas de milho em cada unidade experimental de maneira aleatória, para determinação da altura da planta e inserção da espiga $(\mathrm{cm})$, comprimento de espigas $(\mathrm{cm})$, número de fileiras por espiga, número de grãos por fileira e número de grãos por espiga. Para determinação da produtividade de grãos de milho, as espigas contidas na área útil foram colhidas manualmente, sendo posteriormente submetidas à trilha mecânica com quantificação da produção final.

Os resultados foram submetidos à análise de variância pelo teste $\mathrm{F}$. Os períodos de interferência PAI, PTPI e PCPI da espécie $B$. plantaginea sobre a cultura do milho foram determinados utilizando-se a variável produtividade de grãos $\left(\mathrm{t} \mathrm{ha}^{-1}\right)$. Quanto às demais 
variáveis, aplicou-se o teste de Tukey para comparar os efeitos dos períodos de convivência e de controle entre a planta daninha e a cultura; e o teste da Diferença Mínima Significativa (DMS), para avaliar as diferenças entre os períodos de controle e de convivência sobre as plantas da cultura, em cada tratamento (Pimentel-Gomes, 1990). Realizou-se ainda a análise de correlação linear de Pearson entre as variáveis estudadas para os períodos de controle e de convivência. Todos os dados foram analisados a $5 \%$ de probabilidade de erro, utilizando-se o programa computacional Winstat (Machado et al., 2002).

Os dados de produtividade, padronizados para $13 \%$ de umidade base seca e expressos em t ha ${ }^{-1}$, foram submetidos à análise de regressão pelo modelo de regressão não-linear. Este modelo obedece à seguinte equação logística:

$$
\mathrm{Y}=\frac{\mathrm{a}}{\left[1+\left(\frac{\mathrm{x}}{\mathrm{b}}\right)^{\mathrm{c}}\right]}
$$

em que: $\mathrm{Y}=$ produtividade de grãos; $\mathrm{x}=$ número de dias após a emergência da cultura do milho; $\mathrm{a}=$ produtividade máxima obtida na testemunha limpa; $\mathrm{b}=$ número de dias em que ocorreu $50 \%$ da redução na produtividade máxima; e c $=$ declividade da curva. Com base nas equações de regressão, foram determinados os periodos de interferência de $B$. plantaginea sobre a cultura do milho, subtraindo-se $5 \%$ da produtividade máxima estimada nas equações de regressão em relação ao tratamento mantido na ausência de infestação - valor considerado como custo da adoção de controle químico.

\section{RESULTADOS E DISCUSSÃO}

Na Figura 1 estão representadas as curvas de produtividade de grãos de milho. A convivência com as plantas daninhas começou a afetar a cultura do milho aos 11 dias após a emergência (DAE), denotando-se a necessidade de realizar controle de $B$. plantaginea até os 27 DAE.

O intervalo entre os 11 e 27 DAE caracterizou o período crítico de prevenção à interferência (PCPI). O período em que o milho e as plantas de $B$. plantaginea podem conviver antes que a interferência se instale de maneira a reduzir a produção (PAI) vai até 11 DAE; assim, fica teoricamente evidente que o final

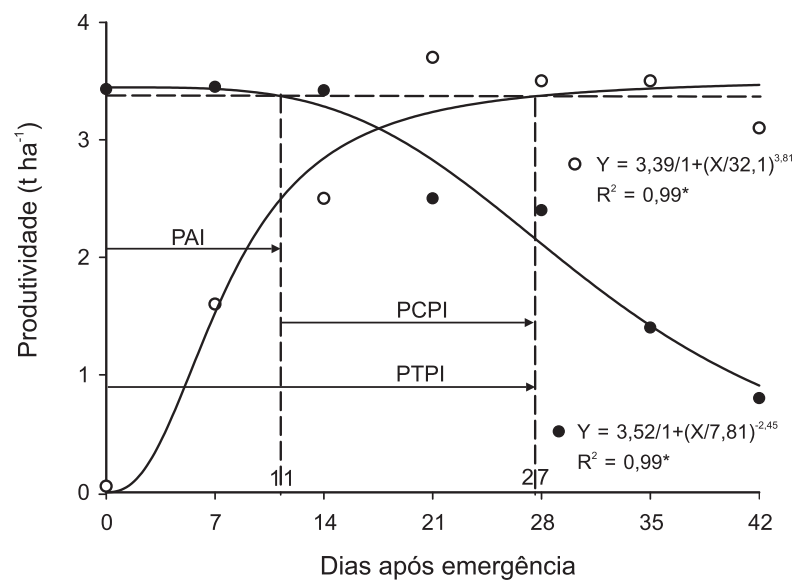

Figura 1 - Produtividade de grãos de milho $\left(\mathrm{t} \mathrm{ha}^{-1}\right)$, em função dos períodos de convivência ( $\mathrm{O}$ ) e de controle $(\mathbf{O})$ de B. plantaginea. PAI: período anterior à interferência; PTPI: período total de prevenção à interferência; PCPI: período crítico de prevenção à interferência. ${ }^{*}$ Significativo a $5 \%$ de probabilidade. CAP/UFPel, Capão do Leão-RS.

do PAI seria a época recomendada para a realização do primeiro controle da espécie infestante.

O período total de prevenção à interferência (PTPI) foi de 27 DAE, ou seja, as plantas de $B$. plantaginea que emergiram após esse período não prejudicaram a produtividade da cultura (Figura 1). Em lavouras onde o controle químico de plantas daninhas é adotado, os herbicidas pré-emergentes devem apresentar efeito residual que abranja o período proposto, já que as plantas que emergirem após essa fase não reduzirão significativamente a produtividade da cultura.

Fica evidente, portanto, que o período em que o milho e as plantas de $B$. plantaginea podem conviver sem que a interferência reflita na redução da produtividade de grãos (PAI) estende-se até os 11 DAE. Já o período em que a cultura do milho deve ficar livre da interferência de plantas de $B$. plantaginea para que a produção não seja afetada (PTPI) vai até os 27 dias, e o período crítico de controle (PCPI) está compreendido entre 11 e 27 DAE da cultura do milho.

O efeito dos períodos de convivência ou de controle sobre a variável estatura das plantas de milho determinada ao final do ciclo da cultura (120 DAE) foi significativo, pois, à medida que se manteve a cultura convivendo com as plantas de B. plantaginea, ocorreu 
paralisação do alongamento em estatura, e, quanto maior a permanência da espécie daninha, maiores foram os danos. Por outro lado, para o período de controle não foram observadas diferenças em todos os períodos estudados, exceto a 0 DAE (Tabela 1). Observou-se ainda não haver diferenças entre os períodos de convivência e de controle na estatura do milho, para os intervalos compreendidos entre 7 e $21 \mathrm{DAE}$. Isso pode ocorrer em função do aumento da população e do desenvolvimento da planta daninha, especialmente daquelas que germinaram e emergiram no início do ciclo da cultura, intensificando a competição inter e intra-específica, de forma que as plantas daninhas de maior estatura tornam-se dominantes, ao passo que as menores são eliminadas da população (Radosevich et al., 1997).

Tabela 1 - Efeito dos períodos de convivência ou de controle de $B$. plantaginea sobre a cultura do milho para a variável estatura de plantas. CAP/UFPel, Capão do Leão-RS

\begin{tabular}{|c|c|c|c|}
\hline \multirow{2}{*}{ Período em DAE $^{1 /}$} & \multicolumn{2}{|c|}{ Estatura de planta $(\mathrm{cm})$} & \multirow{2}{*}{ Diferença $^{3 /}$} \\
\cline { 2 - 3 } & Convivência & Controle & \\
\hline 0 & $182,33 \mathrm{~B}^{2 /}$ & $105,29 \mathrm{~B}^{2}$ & $77,04^{*}$ \\
\hline 7 & $189,73 \mathrm{~A}$ & $181,97 \mathrm{~A}$ & $7,76 \mathrm{~ns}$ \\
\hline 14 & $180,44 \mathrm{BC}$ & $189,23 \mathrm{~A}$ & $-8,79 \mathrm{~ns}$ \\
\hline 21 & $175,23 \mathrm{C}$ & $184,00 \mathrm{~A}$ & $-8,76 \mathrm{~ns}$ \\
\hline 28 & $163,07 \mathrm{D}$ & $181,23 \mathrm{~A}$ & $-18,16^{*}$ \\
\hline 35 & $153,48 \mathrm{E}$ & $175,17 \mathrm{~A}$ & $-21,68^{*}$ \\
\hline 42 & $153,00 \mathrm{E}$ & $181,90 \mathrm{~A}$ & $-27,60^{*}$ \\
\hline Média geral & 171,23 & 171,26 & - \\
\hline CV(\%) & 1,72 & 4,69 & - \\
\hline
\end{tabular}

1/ DAE $=$ dias após a emergência da cultura do milho. ${ }^{2} /$ Médias seguidas pela mesma letra na coluna não diferem entre si pelo teste de Tukey $(\mathrm{p} \leq 0,05) \cdot{ }^{3 /} \mathrm{ns}=$ não-significativo; * significativo a $5 \%$ de probabilidade pelo teste da DMS.

Houve diminuição da altura da inserção da espiga quando a cultura conviveu com as plantas de B. plantaginea (Tabela 2). De maneira geral, observou-se a ocorrência de três patamares diferenciados entre os períodos de convivência e de controle, com mudanças acentuadas e significativas a cada período de 14 dias de desenvolvimento das plantas; os dois periodos geralmente apresentaram diferenciação para as épocas mais tardias da competição com a planta daninha.

Resultados semelhantes aos obtidos neste experimento para as variáveis estatura de
Tabela 2 - Efeito dos períodos de convivência ou de controle de $B$. plantaginea sobre a altura da inserção da primeira espiga nas plantas de milho. CAP/UFPel, Capão do LeãoRS

\begin{tabular}{|c|c|c|c|}
\hline \multirow{2}{*}{ Período em DAE } & \multicolumn{2}{|c|}{ Altura inserção $1^{\underline{\underline{a}}}$ espiga $(\mathrm{cm})$} & \multirow{2}{*}{ Diferença $^{3 /}$} \\
\cline { 2 - 3 } & Convivência & Controle & \\
\hline 0 & $83,10 \mathrm{~A}^{\underline{2}}$ & $55,67 \mathrm{D}^{2}$ & $27,43^{*}$ \\
\hline 7 & $89,03 \mathrm{~A}$ & $88,70 \mathrm{ABC}$ & $0,32 \mathrm{~ns}$ \\
\hline 14 & $84,07 \mathrm{~A}$ & $94,90 \mathrm{~A}$ & $-10,83 \mathrm{~ns}$ \\
\hline 21 & $71,33 \mathrm{~B}$ & $89,23 \mathrm{AB}$ & $-17,89^{*}$ \\
\hline 28 & $71,10 \mathrm{~B}$ & $78,57 \mathrm{C}$ & $-7,46 \mathrm{~ns}$ \\
\hline 35 & $58,90 \mathrm{C}$ & $84,00 \mathrm{BC}$ & $-25,1^{*}$ \\
\hline 42 & $52,80 \mathrm{C}$ & $88,57 \mathrm{ABC}$ & $-35,76^{*}$ \\
\hline Média geral & 72,90 & 82,80 & - \\
\hline $\mathrm{CV}(\%)$ & 6,15 & 5,28 & - \\
\hline
\end{tabular}

$\underline{1} / \mathrm{DAE}=$ dias após a emergência da cultura do milho. ํㅡ Médias seguidas pela mesma letra na coluna não diferem entre si pelo teste de Tukey $(\mathrm{p} \leq 0,05),{ }^{3 /} \mathrm{ns}=$ não-significativo; * significativo a $5 \%$ de probabilidade pelo teste da DMS.

plantas e altura da inserção da primeira espiga foram relatados por Souza (1996) e Zagonel et al. (2000), ao observarem que elas foram afetadas na ausência de controle de plantas daninhas na cultura do milho, em relação ao controle efetuado até os $45 \mathrm{DAE}$. De acordo com Rizzardi et al. (2008), a estatura de plantas e a altura de inserção da primeira espiga de milho foram paralisadas à medida que se efetuou o controle das espécies daninhas em estádio mais tardio de desenvolvimento. Esses autores relatam que isso ocorreu em razão da menor disponibilidade de recursos à cultura do milho devido à competição das plantas daninhas pelos fatores ambientais água, luz e nutrientes.

O comprimento das espigas de milho foi afetado em função da convivência com $B$. plantaginea, sendo os maiores efeitos observados quanto maior o período de convivência entre a cultura e as plantas daninhas (Tabela 3). No entanto, essa variável não diferiu em todos os períodos de controle testados. A exceção foi o 0 DAE, onde ocorreram diferenças entre a convivência e o controle da espécie infestante. Nesse caso, considerando que tanto a convivência como o controle foram delimitados pelo momento da semeadura, a cultura permaneceu livre de infestação em uma situação e constantemente infestada em outra, razão pela qual diferenças significativas foram observadas. Esses resultados corroboram aos 
Tabela 3 - Efeito dos períodos de convivência ou de controle de $B$. plantaginea sobre o comprimento das espigas das plantas da cultura do milho. CAP/UFPel, Capão do LeãoRS

\begin{tabular}{|c|c|c|c|}
\hline \multirow{2}{*}{ Período em DAE $^{1 /}$} & \multicolumn{2}{|c|}{ Comprimento da espiga $(\mathrm{cm})$} & \multirow{2}{*}{ Diferença ${ }^{3 /}$} \\
\cline { 2 - 3 } & Convivência & Controle & \\
\hline 0 & $16,18 \mathrm{AB}^{2 /}$ & $3,11 \mathrm{~B}^{2}$ & $13,06 *$ \\
\hline 7 & $15,73 \mathrm{AB}$ & $13,73 \mathrm{~A}$ & $1,99 \mathrm{~ns}$ \\
\hline 14 & $16,65 \mathrm{~A}$ & $15,67 \mathrm{~A}$ & $0,98 \mathrm{~ns}$ \\
\hline 21 & $15,34 \mathrm{AB}$ & $15,81 \mathrm{~A}$ & $-0,47 \mathrm{~ns}$ \\
\hline 28 & $15,71 \mathrm{AB}$ & $16,10 \mathrm{~A}$ & $-0,38 \mathrm{~ns}$ \\
\hline 35 & $14,34 \mathrm{BC}$ & $15,99 \mathrm{~A}$ & $-1,65 \mathrm{~ns}$ \\
\hline 42 & $13,23 \mathrm{C}$ & $16,20 \mathrm{~A}$ & $-2,96 \mathrm{~ns}$ \\
\hline Média geral & 15,31 & 13,80 & - \\
\hline $\mathrm{CV}(\%)$ & 5,46 & 11,72 & - \\
\hline
\end{tabular}

${ }^{1 /} \mathrm{DAE}=$ dias após a emergência da cultura do milho. ${ }^{2 /}$ Médias seguidas pela mesma letra na coluna não diferem entre si pelo teste de Tukey $(\mathrm{p} \leq 0,05),{ }^{3 /} \mathrm{ns}=$ não-significativo; * significativo a $5 \%$ de probabilidade pelo teste da DMS.

encontrados por Zagonel et al. (2000), os quais verificaram a diminuição do número de espiga por planta de milho com atraso na época de controle das plantas daninha em conseqüência da mato-competição. Esses autores relatam ainda que o controle de plantas daninhas efetuado a partir de 2 DAE reflete-se positivamente nos componentes de rendimento de grãos da cultura do milho.

Quanto ao número de fileiras de grãos por espiga, observou-se que, mantendo-se a cultura convivendo com a planta daninha até os $27 \mathrm{DAE}$, não houve alteração significativa, enquanto para o período de controle ocorreu efeito inverso. Analisando o período de controle, observa-se que somente houve diferença quando a cultura ficou convivendo durante todo o período de avaliação com $B$. plantaginea (Tabela 4). Resultados semelhantes foram observados por Zagonel et al. (2000), ao relatarem que, quanto maior o período de convivência da cultura do milho com as plantas daninhas, menor será o número de fileiras por espiga.

A convivência da cultura do milho com a planta daninha em estudo, de maneira geral, afetou o número de grãos por fileira, observando-se que, quanto maior a permanência da cultura com a espécie infestante, mais elevados são os danos (Tabela 5). Assim, operações de controle realizadas precocemente (O DAE) ou mais tardias (após $14 \mathrm{DAE}$ ) podem interferir
Tabela 4 - Efeito dos períodos de convivência ou de controle de $B$. plantaginea sobre o número de fileira de grãos por espiga de milho. CAP/UFPel, Capão do Leão-RS

\begin{tabular}{|c|c|c|c|}
\hline \multirow{2}{*}{ Período em DAE $^{\underline{1}}$} & \multicolumn{2}{|c|}{ Número de fileira por espiga } & \multirow{2}{*}{ Diferença $^{3 /}$} \\
\cline { 2 - 3 } & Convivência & Controle & \\
\hline 0 & $14,05 \mathrm{~A}^{2}$ & $4,00 \mathrm{~B}^{2}$ & $10,05^{*}$ \\
\hline 7 & $14,85 \mathrm{~A}$ & $13,75 \mathrm{~A}$ & $1,1 \mathrm{~ns}$ \\
\hline 14 & $14,85 \mathrm{~A}$ & $14,30 \mathrm{~A}$ & $0,55 \mathrm{~ns}$ \\
\hline 21 & $13,95 \mathrm{~A}$ & $14,60 \mathrm{~A}$ & $-0,65 \mathrm{~ns}$ \\
\hline 28 & $13,95 \mathrm{~A}$ & $14,15 \mathrm{~A}$ & $-0,2 \mathrm{~ns}$ \\
\hline 35 & $12,3 \mathrm{~B}$ & $14,55 \mathrm{~A}$ & $-2,25 \mathrm{~ns}$ \\
\hline 42 & $11,55 \mathrm{~B}$ & $13,90 \mathrm{~A}$ & $-2,35 \mathrm{~ns}$ \\
\hline Média geral & 13,64 & 12,75 & - \\
\hline CV(\%) & 3,94 & 14,56 & - \\
\hline
\end{tabular}

${ }^{1 /} \mathrm{DAE}=$ dias após a emergência da cultura do milho. ${ }^{2 /}$ Médias seguidas pela mesma letra na coluna não diferem entre si pelo teste de Tukey $(\mathrm{p} \leq 0,05) \cdot{ }^{3 /} \mathrm{ns}=$ não-significativo; * significativo a $5 \%$ de probabilidade pelo teste da DMS.

Tabela 5 - Efeito dos períodos de convivência ou de controle de $B$. plantaginea sobre o número de grãos por fileira em cada espiga de milho. CAP/UFPel, Capão do Leão-RS

\begin{tabular}{|c|c|c|c|}
\hline \multirow{2}{*}{ Período em DAE $^{1 /}$} & \multicolumn{2}{|c|}{ Número de grãos por fileira } & \multirow{2}{*}{ Diferença $^{3 /}$} \\
\cline { 2 - 3 } & Convivência & Controle & \\
\hline 0 & $29,83 \mathrm{AB}^{\frac{2}{}}$ & $5,05 \mathrm{~B}^{\underline{2} /}$ & $24,77^{*}$ \\
\hline 7 & $31,90 \mathrm{~A}$ & $24,43 \mathrm{~A}$ & $7,47^{*}$ \\
\hline 14 & $31,20 \mathrm{~A}$ & $27,30 \mathrm{~A}$ & $3,90 \mathrm{~ns}$ \\
\hline 21 & $25,67 \mathrm{BC}$ & $31,40 \mathrm{~A}$ & $-5,73 \mathrm{~ns}$ \\
\hline 28 & $26,20 \mathrm{BC}$ & $29,07 \mathrm{~A}$ & $-2,86 \mathrm{~ns}$ \\
\hline 35 & $23,85 \mathrm{CD}$ & $28,10 \mathrm{~A}$ & $-4,25 \mathrm{~ns}$ \\
\hline 42 & $20,48 \mathrm{D}$ & $30,35 \mathrm{~A}$ & $-9,87^{*}$ \\
\hline Média geral & 27,07 & 25,10 & - \\
\hline CV(\%) & 6,84 & 12,98 & - \\
\hline
\end{tabular}

${ }^{1 /} \mathrm{DAE}=$ dias após a emergência da cultura do milho. ${ }^{2 /}$ Médias seguidas pela mesma letra na coluna não diferem entre si pelo teste de Tukey $(\mathrm{p} \leq 0,05) \cdot{ }^{3 /} \mathrm{ns}=$ não-significativo; * significativo a $5 \%$ de probabilidade pelo teste da DMS.

no processo de formação dos componentes da espiga, afetando a produtividade de grãos da cultura do milho. Esses resultados são decorrentes do fato de que a planta de milho necessita estar no limpo no período compreendido entre a sétima e nona folhas completamente expandidas, para que não haja interferência no processo de diferenciação floral da gema que dará origem à espiga. Logo após essa diferenciação, rapidamente a planta determina os 
números de fileiras por espigas e de grãos por fileira que farão parte da composição da futura espiga (Fancelli \& Dourado Neto, 2000).

Quanto ao total de grãos por espiga, três niveis de diferenciação puderam ser observados para os períodos de convivência e de controle da cultura com a planta daninha (Tabela 6). No entanto, a convivência afetou a cultura para a variável em estudo à medida que esta foi deixada na presença da espécie infestante, com redução de aproximadamente $50 \%$ no número total de grãos, ao se comparar o período de infestação (O DAE) com o infestado durante todo o período de avaliação (42 DAE). Ao se efetuar o controle de $B$. plantaginea, observou-se incremento no número total de grãos por espiga, pois, à medida que o controle foi realizado mais cedo, maiores incrementos foram observados, superando os $1000 \%$ ao se comparar 0 DAE com 42 DAE. Também se observaram efeitos entre os dois periodos em estudo; as maiores diferenças foram constatadas nos extremos.

Tabela 6 - Efeito dos períodos de convivência ou de controle de B. plantaginea sobre o total de grãos em cada espiga de milho. CAP/UFPel, Capão do Leão-RS

\begin{tabular}{|c|c|c|c|}
\hline \multirow{2}{*}{ Período em DAE $^{1 /}$} & \multicolumn{2}{|c|}{ Total de grãos por espiga } & \multirow{2}{*}{ Diferença $^{\text {3/ }}$} \\
\cline { 2 - 3 } & Convivência & Controle & \\
\hline 0 & $436,08 \mathrm{~A}^{\underline{2}}$ & $40,94 \mathrm{C}^{2} /$ & $395,14^{*}$ \\
\hline 7 & $454,65 \mathrm{~A}$ & $312,81 \mathrm{~B}$ & $141,83^{*}$ \\
\hline 14 & $463,24 \mathrm{~A}$ & $430,27 \mathrm{~A}$ & $32,96 \mathrm{~ns}$ \\
\hline 21 & $347,22 \mathrm{~B}$ & $443,27 \mathrm{~A}$ & $-96,04 *$ \\
\hline 28 & $364,87 \mathrm{~B}$ & $410,67 \mathrm{~A}$ & $-45,79 \mathrm{~ns}$ \\
\hline 35 & $311,54 \mathrm{~B}$ & $444,27 \mathrm{~A}$ & $-132,72 *$ \\
\hline 42 & $216,66 \mathrm{C}$ & $431,07 \mathrm{~A}$ & $-214,36 *$ \\
\hline Média geral & 370,61 & 359,04 & - \\
\hline CV(\%) & 6,25 & 9,36 & - \\
\hline
\end{tabular}

1/ DAE = dias após a emergência da cultura do milho. ${ }^{2 /}$ Médias seguidas pela mesma letra na coluna não diferem entre si pelo teste de Tukey $(\mathrm{p} \leq 0,05) \cdot{ }^{3 /} \mathrm{ns}=$ não-significativo; * significativo a $5 \%$ de probabilidade pelo teste da DMS.

É importante ressaltar ainda que todas as variáveis estudadas se correlacionaram a $1 \%$ de probabilidade, tanto em relação ao período de convivência da cultura com as plantas daninhas (Tabela 7) quanto ao período de controle destas (Tabela 8). Assim, a partir da análise de qualquer uma das variáveis, é possivel que se façam aferições sobre o comportamento das demais relacionadas a ela, mesmo antes de a cultura atingir estádio de desenvolvimento em que seja possivel a avaliação direta da variável de interesse.

A convivência da planta daninha com a cultura afetou a produtividade do milho, e a análise de correlação indicou que $92 \%$ da variação da produtividade de grãos foi determinada pelo número de grãos por espiga $x$ número de grãos por fileira; já a produtividade de grãos $\mathrm{x}$ altura da inserção da primeira espiga e a produtividade de grãos $x$ grãos por espiga explicaram $89 \%$ da variação da interferência de $B$. plantaginea sobre o milho. Obteve-se a menor correlação para altura de plantas x comprimento da espiga, com 59\% da explicação da interferência de $B$. plantaginea sobre a cultura (Tabela 7). De acordo com Mundstock \& Silva (1989), o número de grãos por espiga representa um dos principais componentes do rendimento da cultura do milho.

Na Tabela 8 observa-se que a menor correlação foi para a produtividade de grãos $\mathrm{x}$ altura de inserção da primeira espiga, com $64 \%$ da explicação da menor produtividade de grãos de milho quando se efetuou o controle da espécie infestante, sendo as maiores correlações denotadas para as variáveis número de grãos por espiga $\mathrm{x}$ número de grãos por fileira, número de grão por espiga $x$ comprimento da espiga, número de grão por espiga $\mathrm{x}$ comprimento da espiga, com 95, 96 e 96\% das explicações, respectivamente. Esses fatos demonstram que o controle de $B$. plantaginea na cultura do milho contribui para incremento nos componentes do rendimento de grãos, ao se comparar com os valores obtidos para os períodos de convivência cultura/planta daninha, e conseqüentemente no aumento da produtividade da cultura em função da eliminação da competitividade de $B$. plantaginea sobre o milho, principalmente nas fases iniciais de desenvolvimento, já que estas são consideradas críticas à cultura (Spader \& Vidal, 2000).

É conveniente destacar que outros pesquisadores constataram redução em outros componentes da produção de grãos de milho, como o número de espigas por planta (Rossi et al., 1996; Zagonel et al., 2000), e na população final do milho (Ramos \& Pitelli, 1994) com o atraso 
Tabela 7 - Matriz de correlação linear de Pearson entre as variáveis, para o período de convivência de $B$. plantaginea sobre a cultura do milho. CAP/UFPel, Capão do Leão-RS

\begin{tabular}{|c|c|c|c|}
\hline Variável & Interação & Variável & Interação \\
\hline Produtividade de grãos $\mathrm{x}$ altura de plantas & $0,74 * *$ & Altura de planta $\mathrm{x}$ inserção da $1^{\underline{a}}$ espiga & $0,87 * *$ \\
\hline Produtividade de grãos $\mathrm{x}$ altura inserção da $1^{\underline{a}}$ espiga & $0,89 * *$ & Altura de plantas $\mathrm{x}$ comprimento da espiga & $0,59 * *$ \\
\hline Produtividade de grãos $\mathrm{x} \mathrm{n}^{\circ}$ de fileira por espiga & $0,86 * *$ & Altura de plantas $\mathrm{x} \mathrm{n}^{\circ}$ de fileiras por espiga & $0,79 * *$ \\
\hline Produtividade de grãos $\mathrm{x}$ comprimento da espiga & $0,83 * *$ & Altura de plantas $\mathrm{x} \mathrm{n}^{\mathrm{o}}$ de grãos por fileiras & $0,77 * *$ \\
\hline Produtividade de grãos $\mathrm{x} \mathrm{n}^{\circ}$ de grãos por fileira & $0,87 * *$ & Inserção da $1^{\mathrm{a}}$ espiga $\mathrm{x}$ comprimento da espiga & $0,76^{* *}$ \\
\hline Produtividade de grãos $\mathrm{x} \mathrm{n}^{\circ}$ de grãos por espiga & $0,89 * *$ & Inserção da $1^{\underline{a}}$ espiga $x \mathrm{n}^{\mathrm{o}}$ de fileiras por espiga & $0,84 * *$ \\
\hline $\mathrm{N}^{\underline{0}}$ de grãos por espiga $\mathrm{x} \mathrm{n}^{\mathrm{o}}$ de grãos por fileira & $0,92 * *$ & Inserção da $1^{\mathrm{a}}$ espiga $\mathrm{x} \mathrm{n}^{\mathrm{o}}$ de grãos por fileira & $0,83 * *$ \\
\hline $\mathrm{N}^{0}$ de grão por espiga $\times \mathrm{n}^{\mathrm{o}}$ de fileira por espiga & $0,84 * *$ & Comprimento da espiga $\mathrm{x} \mathrm{n}^{\mathrm{o}}$ fileiras por espiga & $0,83 * *$ \\
\hline № de grão por espiga $x$ comprimento da espiga & $0,77 * *$ & Comprimento da espiga $\times \mathrm{n}^{\circ}$ de grãos por fileira & $0,80 * *$ \\
\hline$^{0}$ de grão por espiga $x$ altura inserção da $1^{\underline{a}}$ espiga & $0,89 * *$ & $\mathrm{~N}^{\mathrm{o}}$ de fileiras $\mathrm{x}$ de grãos por fileira & $0,80 * *$ \\
\hline $\mathrm{N}^{\mathrm{o}}$ de grão por espiga $\mathrm{x}$ altura de plantas & $0,81 * *$ & & \\
\hline
\end{tabular}

** Significativo a $1 \%$ pela análise de correlação linear de Pearson.

Tabela 8 - Matriz de correlação linear de Pearson entre as variáveis, para o período de controle de B. plantaginea sobre a cultura do milho. CAP/UFPel, Capão do Leão-RS

\begin{tabular}{|c|c|c|c|}
\hline Variável & Interação & Variável & Interação \\
\hline Produtividade de grãos $\mathrm{x}$ altura de plantas & $0,71 * *$ & Altura de plantas x inserção da $1^{\underline{a}}$ espiga & $0,90 * *$ \\
\hline Produtividade de grãos $\mathrm{x}$ altura inserção da $1^{\mathrm{a}}$ espiga & $0,64 * *$ & Altura de plantas $\mathrm{x}$ comprimento da espiga & $0,94 * *$ \\
\hline Produtividade de grãos $\mathrm{x} n$. de fileira por espiga & $0,71 * *$ & Altura de plantas $\mathrm{x} n$. de fileiras por espiga & $0,92 * *$ \\
\hline Produtividade de grãos $\mathrm{x}$ comprimento da espiga & $0,80 * *$ & Altura de plantas $\mathrm{x} n$. de grãos por fileiras & $0,93 * *$ \\
\hline Produtividade de grãos $\mathrm{x} n$. de grãos por fileira & $0,83 * *$ & Inserção da $1^{\mathrm{a}}$ espiga $\mathrm{x}$ comprimento da espiga & $0,83 * *$ \\
\hline Produtividade de grãos $\mathrm{x} n$. de grãos por espiga & $0,85 * *$ & Inserção da $1^{\mathrm{a}}$ espiga $\mathrm{x} \mathrm{n}^{\mathrm{o}}$ de fileiras por espiga & $0,83 * *$ \\
\hline $\mathrm{N}^{\mathrm{o}}$ de grãos por espiga $\mathrm{x} n$. de grãos por fileira & $0,95 * *$ & Inserção da $1^{\text {a }}$ espiga $\mathrm{x} \mathrm{n}^{\circ}$ de grãos por fileira & $0,83 * *$ \\
\hline $\mathrm{N}^{\mathrm{o}}$ de grão por espiga $\mathrm{x} n$. de fileira por espiga & $0,91 * *$ & Comprimento da espiga $\mathrm{x} \mathrm{n}^{\mathrm{0}}$ fileiras por espiga & $0,96 * *$ \\
\hline $\mathrm{N}^{0}$ de grão por espiga $\mathrm{x}$ comprimento da espiga & $0,96 * *$ & Comprimento da espiga $\times \mathrm{n}^{\circ}$ de grãos por fileira & $0,93 * *$ \\
\hline $\mathrm{N}^{\mathrm{o}}$ de grão por espiga $\mathrm{x}$ altura inserção da $1^{\underline{a}}$ espiga & $0,83 * *$ & N. de fileiras por espiga $x n^{0}$ de grãos por fileira & $0,93 * *$ \\
\hline $\mathrm{N}^{\mathrm{o}}$ de grão por espiga $\mathrm{x}$ altura de plantas & $0,91 * *$ & & \\
\hline
\end{tabular}

** Significativo a $1 \%$ pela análise de correlação linear de Pearson.

na época de controle, em conseqüência da mato-competição. Isso ocorre principalmente quando tanto as espécies daninhas quanto as culturas apresentam características morfofisiológicas semelhantes, fazendo assim com que as exigências em nutrientes, água, espaço e luz sejam semelhantes, tornando-se mais intensa a competição pelos fatores do meio (Radosevich et al., 1997); desse modo, algum método de controle necessita ser implementado para que não ocorra queda de produtividade da cultura.

Neste trabalho, determinou-se o período crítico de prevenção da interferência em função de DAE e não por estádio de desenvolvimento da cultura. No entanto, essa metodologia pode não ser apropriada, pelo fato de que o estádio fenológico é que define os tratos culturais nas culturas. Entretanto, de acordo com Vidal et al. (2005), a definição do período de convivência das plantas daninhas pelo estádio fenológico também não é totalmente apropriada, pois leva em consideração apenas um dos componentes do sistema, a cultura, deixando de considerar as espécies daninhas. Além disso, conforme esses autores, a cultura do milho, quando semeada em período frio, pode levar até $50 \mathrm{DAE}$ para atingir o estádio $\mathrm{V}_{3}$. Contudo, na comunidade infestante da cultura poderá haver espécies adaptadas a se desenvolverem adequadamente nessas condições, de forma que, quando a cultura estiver no referido estádio de desenvolvimento, as plantas daninhas 
já terão dominado o nicho, comprometendo seriamente a produtividade de grãos da cultura.

De acordo com os resultados obtidos e utilizando observações de Pitelli \& Durigan (1984), conclui-se que o período total de prevenção à interferência (PTPI) foi de 27 dias e a duração do período que antecede a interferência (PAI), de 11 dias, ambos contados a partir da emergência da cultura do milho. Assim, evidenciase neste estudo que o controle das plantas de $B$. plantaginea deve ser iniciado no período de 11 a 27 dias após a emergência, dentro do período considerado como crítico de prevenção à interferência (PCPI), possibilitando à cultura expressar todo o seu potencial produtivo, de acordo com as condições edafoclimáticas 1ocais.

A definição do PCPI na cultura do milho e em outras culturas é uma ferramenta de extrema importância para a adoção do manejo integrado das plantas daninhas, a fim de se evitarem perdas e uso desnecessário de herbicidas. Contudo, a determinação precisa desse período é complexa, pois fatores como época de semeadura e população de plantas da cultura; dose e épocas de aplicação da adubação nitrogenada; espécies e populações de plantas daninhas presentes na área; e características edafoclimáticas podem influenciar consideravelmente os resultados, ocasionando diferenças em locais e anos distintos.

\section{LITERATURA CITADA}

BALBINOT JR., A. A.; FLECK, N. G. Competitividade de dois genótipos de milho (Zea mays) com plantas daninhas sob diferentes espaçamentos entre fileiras. Planta Daninha, v. 23 , n. 3, p. $415-421,2005$.

CARVALHO, L. B. et al. Estudo comparativo do acúmulo de massa seca e macronutrientes por plantas de milho var. BR106 e Brachiaria plantaginea. Planta Daninha, v. 25, n. 2, p. 293-301, 2007.

COMPANHIA NACIONAL DE ABASTECIMENTO CONAB: Indicadores da agropecuária. Disponível em: <http://www.conab.gov.br>. Acesso em: 27de nov. de 2007.

CONSTANTIN, J. et al. Interação entre sistemas de manejo e de controle de plantas daninhas em pós-emergência afetando o desenvolvimento e a produtividade do milho. Planta Daninha, v. 25, n. 3, p. 513-520, 2007.
DUARTE, A. P.; SILVA, A. C.; DEUBER, R. Plantas infestantes em lavouras de milho safrinha, sob diferentes manejos, no médio Paranapanema. Planta Daninha, v. 25, n. 2, p. $285-291,2007$.

\section{EMPRESA BRASILEIRA DE PESQUISA}

AGROPECUÁRIA - EMBRAPA. Centro Nacional de Pesquisa Agropecuária de Solos. Sistema brasileiro de classificação de solos. Brasília: Embrapa Produção de Informação; Rio de Janeiro: Embrapa Solos, 1999. 412 p.

FANCELLI, L. A.; DOURADO NETO, D. Manejo de plantas daninhas. In: FANCELLI, L. A.; DOURADO NETO, D. (Eds.). Produção de milho. Guaíba: Agropecuária, 2000. p. $183-215$

FLECK, N. G. Interferência de papuã (Brachiaria plantaginea) com soja e ganho de produtividade obtido através do seu controle. Pesq. Agropec. Gaúcha, v. 2, n. 1, p. 63-68, 1996.

HAAN, R. L. et al. Simulation of springseeded smother plants for weed control in corn (Zea mays). Weed Sci., v. 42, n. 1, p. $35-43,1994$.

HALL, M. R.; SWANTON, C. J.; ANDERSON, G. W. The critical period of weed control in grain corn (Zea mays). Weed Sci., v. 40, n. 3, p. 441-447, 1992

INDICAÇÕES técnicas para o cultivo de milho e de sorgo no Rio Grande do Sul - 2006. In: REUNIÃO TÉCNICA ANUAL DE MILHO, 51., 2006, Passo Fundo. Anais... Passo Fundo: 2006. 84 p.

KISSMANN, K. G.; GROTH, D. Plantas infestantes e nocivas. 2.ed. São Paulo: BASF, 1997. Tomo I. 825 p.

MACHADO, A. A. et al. Sistema de análises estatísticas para Windows - WINSTAT (Versão 2.11). Pelotas: Núcleo de Informação Aplicada - Universidade Federal de Pelotas, 2002.

MEROTTO Jr., A. et al. Aumento da população de plantas e uso de herbicidas no controle de plantas daninhas em milho.

Planta Daninha, v. 15, n. 2, p. 141-151, 1997.

MUNDSTOCK, C. M.; SILVA, P. R. F. Manejo da cultura do milho. Porto Alegre: Universidade do Rio Grande do Sul, 1989. $76 \mathrm{p}$

PIMENTEL-GOMES, F. Curso de estatística experimental. Piracicaba: Nobel, 1990. 468 p.

PITELLI, R. A.; DURIGAN, J. C. Terminologia para períodos de controle e convivência das plantas daninhas em culturas anuais e bianuais. In: CONGRESSO BRASILEIRO DE HERBICIDAS E PLANTAS DANINHAS, 15., 1984, Belo Horizonte. Resumos... Belo Horizonte: SBCPD, 1984. p. 37.

Planta Daninha, Viçosa-MG, v. 26, n. 4, p. 779-788, 2008 
PITELLI, R. A. Interferências de plantas daninhas em culturas agrícolas. Inf. Agropec., v. 11, p. 16-27, 1985.

RADOSEVICH, S.; HOLT, J.; GHERSA, C. Weed ecology: Implications for vegetation management. 2.ed. New York: Wiley, 1997. 589 p

RAMOS, L. R. M.; PITELLI, R.A. Efeitos de diferentes períodos de controle da comunidade infestante sobre a produtividade da cultura do milho. Pesq. Agropec. Bras., v. 29, n. 10, p. $1523-1531,1994$.

INDICAÇÕES técnicas para o cultivo de milho e de sorgo no Rio Grande do Sul - 2006. In: REUNIÃO TÉCNICA ANUAL DE MLLHO, 51., 2006, Passo Fundo. Anais... Passo Fundo: 2006. 84 p

RIZZARDI, M. A.; KARAM, D.; CRUZ, M. B. Manejo e controle de plantas daninhas em milho e sorgo. In: VARGAS, L.; ROMAN, E. S. Manual de manejo e controle de plantas daninhas. Bento Gonçalves: Embrapa Uva e Vinho, 2004. p. $571-594$

RIZZARDI, M. A. et al. Controle de plantas daninhas em milho em função de épocas de aplicação de nitrogênio Planta Daninha, v. 26, n. 1, p. 113-121, 2008

ROSSI, I. H. et al. Interferência das plantas daninhas sobre algumas características agronômicas e a produtividade de sete cultivares de milho. Planta Daninha, v. 14, n. 2, p. 134148, 1996.

SALES, J. L. Determinação dos períodos de interferência e integração de práticas culturais com herbicidas no controle de plantas daninhas na cultura do milho (Zea mays L.). 1991. 151 f. Tese (Doutorado em Fitotecnia) - Escola Superior de Agricultura Luiz de Queiroz, Piracicaba, 1991.
SEVERINO, F. J.; CARVALHO, S. J. P.; CHRISTOFFOLETI, P. J. Interferências mútuas entre a cultura do milho, espécies forrageiras e plantas daninhas em um sistema de consórcio. I - implicações sobre a cultura do milho (Zea mays). Planta Daninha, v. 23, n. 4, p. 589-596, 2005.

SILVA, A. F. et al. Densidades de plantas daninhas e épocas de controle sobre os componentes de produção da soja. Planta Daninha, v. 26, n. 1, p. 65-71, 2008

SINGH, M. et al. Estimation of critical period of weed control. Weed Sci., v. 44, n. 2, p. 273-283, 1996

SOUZA, J. R. P. Período de controle das plantas daninhas, crescimento e produtividade da cultura do milho (Zea mays L.). 1996. 91 f. Tese (Doutorado em Agronomia) - Universidade Estadual de São Paulo, Botucatu, 1996.

SPADER, V.; VIDAL, R. A. Interferência de Brachiaria plantaginea sobre características agronômicas, componentes do rendimento e produtividade de grãos do milho. Planta Daninha, v. 18 , n. 3, p. 465-470, 2000.

VIDAL, R. A. et al. Nível de dano econômico de Brachiaria plantaginea na cultura de milho irrigado. Planta Daninha, v. 22, n. 1, p. $63-69,2004$

VIDAL, R. A.; FLECK, N. G.; MEROTTO JR., A. Período anterior ao dano no rendimento econômico (PADRE): nova abordagem sobre os períodos de interferência entre plantas daninhas e cultivadas. Planta Daninha, v. 23, n. 3, p. 387396,2005 .

ZAGONEL, J.; VENÂNCIO. W. S.; KUNZ, R. P. Efeito de métodos e épocas de controle das plantas daninhas na cultura do milho. Planta Daninha, v. 18, n. 1, p. 143-150, 2000 . 